\title{
The Characteristics and Its Application of Cloud Accounting under the Background of Big Data
}

\author{
Yiwen Lu \\ Oxbridge College, Kunming University of Science and Technology, \\ Kunming City, Yunnan Province, 650106, China
}

\begin{abstract}
The Internet, mobile communication and all kinds of new wireless application technologies have greatly changed the internal operation model and external transaction model in traditional enterprises and big data has become a valuable resource for enterprises. Cloud accounting comes into being, which is a new accounting model based on cloud computing in the environment of big data. The cloud accounting not only reduces enterprises' input of manpower, material resources and capital investment, but also greatly enhances the efficiency of the enterprise information data processing, which becomes an effective way for enterprises to manage accounting information system. Based on the author's learning and practical experience, this paper first analyzed the characteristics of cloud accounting, then discussed the application status of cloud accounting. Finally, the article proposed the application strategies of cloud accounting. Keywords: Big data; Cloud accounting; Characteristics; Application
\end{abstract}

\section{Introduction}

The new business model created by cloud accounting has a significant impact on existing accounting theory and practice system. The application of the cloud computing is based on use distribution, parallel processing and network, which makes enterprises face many practical obstacles, such as system security, data authenticity and imperfect internal control system[1]. Therefore, the application 
of the cloud accounting in the new business model becomes the focus of theoretical circles and accounting practitioners.

\section{Characteristics of Cloud Accounting}

Cloud computing is a new product of the information society. The application of cloud computing in accounting data produces cloud accounting. The Twelfth Five-Year Plan of Accounting Reform and Development issued by the Ministry of Finance clearly states that the government will take the promotion of accounting informationization as an important measure to achieve scientific and precise accounting management. The application of cloud accounting in accounting information system can promote the information construction of enterprise accounting and cloud accounting is a long-term driving force for enterprise development, so the application of cloud accounting in enterprise finance is one of the problems which needs to be solved urgently. Cloud accounting focuses on the enterprise management accounting and financial decision-making, so that enterprises focus on operating management and outsource the information construction and service of the accounting. This model will further promote the accounting development[2]. Cloud accounting involves the cloud service providers and business users. Cloud service providers not only provide relevant cloud accounting services for enterprise users, such as accounting checking system, management information system, business decision making system and other business systems, but also provide relevant cloud accounting service platforms for business users, such as the cloud accounting database service platform, and accounting information development and application platform. Enterprise users pay for cloud accounting services.

\section{The Application Status of Cloud Accounting}

\subsection{The application of cloud accounting is in the initial stage and its promotion needs to be improved}

According to the survey, less than $10 \%$ of enterprises use cloud computing technology to carry out related business in China currently. The reason is mainly that technology in this field is immature. The need of establishing and improving capital platform creates cloud accounting which requires high research and development expenditure and time cost. This makes it difficult for financial data platform to achieve the level of independent research and development. With the limitations of information processing and information control, enterprises in China still face many difficulties in applying cloud accounting to improve their financial management system[3]. Besides, China's promotion of cloud accounting is not enough, which results in that China does not have a mature cloud computing platform as the developed countries. At present, the scope of 
government policies to support cloud accounting is small and there is no clear standards, laws and regulations about the application of cloud accounting, which resulting in that many people do not accept the application of cloud accounting[4].

\subsection{The development of network technology limits the wide application of cloud accounting}

The application of cloud accounting to accounting information system is largely limited and affected by the speed of information cloud computing. For example, the complexity of the data resource process and different data access rights lead to the failure of data exchange and transmission. Therefore, the development of network technology affects the detection of network node failure and its recovery capability. In the detection of network load, the application system which gives an alarm and conducts assistance management cannot achieve the relevant standards of cloud accounting in the dynamic delivery.

\subsection{Cloud accounting services are mainly distributed in the low-end enterprises}

In China's current situation, cloud accounting-related services are mainly distributed in the low-end enterprises and most of these companies rely on low cost to occupy the market. Therefore, functions of relevant cloud services and financial accounting software are limited to some simple data processing. It presents mainly in two aspects: first is to provide online accounting and financial management services, which mainly meets data processing needs of middle and small-sized enterprises in their daily financial activities; the second is to provide customers with marketing data and plan, network account accounting and other applications[5]. These cannot meet enterprises' further need of cloud accounting. The cloud accounting takes cloud computing as the core of data processing and it can use integrated software which may meet the safety standards and data processing needs according to the requirements of actual business to financial accounting and management information. China's enterprises have not applied all functions of cloud accounting yet.

\subsection{Enterprises' recognition degree of information security and privacy is low}

Cloud service providers tend to implement strict security testing standards to ensure system security and privacy, but users are still inevitably worried about the reserves of financial data information in the cloud. Users can not solve the automatic system failure by themselves, until the cloud provider solves this problem, which causes great trouble for users who need rapid access to data. In addition, the privacy of information is often a stumbling block for the extensive application of cloud accounting[6]. As the calculation model of cloud accounting allows a server to retain the financial data of many enterprises, many companies believe that this model will divulge the company's financial data and more secrets. Users fear that corporate privacy data will be accessed or theft by others. Many 
concerns lead to that the application of cloud accounting to the financial accounting system in the domestic enterprises makes slow progress.

\section{The Application Strategies of Cloud Accounting}

\subsection{To strengthen the construction of the cloud accounting computing platform}

The construction of the cloud accounting computing platform is a guarantee for enterprises to achieve the cloud accounting computing, and the construction needs funds and technical support. However, there exists a high risk and the development cycle is long. Therefore, the government should introduce relevant policies to support and encourage the domestic IT enterprises to research and develop the cloud accounting system independently. They can overcome the problem of funds by virtue of government subsidies or preferential measures effectively. Domestic IT companies should research and develop the cloud accounting system combining with the actual situation of China's enterprises. In addition, companies should learn from experience of well-known and mature cloud computing platforms in other countries, such as Google in the U.S, Amazon and other IT companies to develop cloud computing platform which are applicable to enterprises in China.

\subsection{To enhance professionalization of the accounting information processing and other services}

The platform needs to improve the online customization and dynamic demand services. Enterprises will propose online customization requirements based on the operating capital and development goals. Therefore, cloud accounting should timely adjust the appropriate financial functions and data integration approaches, and update the application software of service information to adapt to the dynamic business demand. Besides, companies should develop private cloud services to enhance the research and development speed of personalized cloud software. Diversified cloud computing services promote the continuous development of the accounting industry chain. Besides, enterprises can rent diversified cloud computing platforms to achieve the vision of private cloud services. Cloud computing service providers need to provide private programming languages and applications tools which support cloud computing to targeted enterprises, so that companies can use personalized cloud accounting applications to meet their needs of the privatization of business information.

\subsection{To establish a risk assessment mechanism of cloud accounting}

Enterprises will use cloud accounting only when they think that the accounting information is safe. Differences in the enterprise operating model, organizational form and management model propose different credibility requirements of cloud 
accounting security. Besides, as the market competition environment changes, the safety of cloud accounting combination which is set by cloud accounting service providers changes. Moreover, this security is based on users' security needs and business needs. Therefore, it is necessary to establish a security risk credibility evaluation mechanism of accounting information in cloud accounting. This aims to understand the possible flaws and potential threats of cloud accounting information system, to meet the changing security needs of enterprises and to eliminate enterprises' security concerns of cloud accounting, so as to promote enterprises to apply cloud accounting[7].

\subsection{To improve related supporting laws and regulations of cloud accounting}

First of all, the state should pay full attention to the application development of cloud accounting which is related to the modernization and digitization of the financial management in large, middle and small-sized enterprises. The government should include the high-end application platform and software development based on cloud computing into the scientific strategic support of emerging industries. Besides, the government needs to improve the cloud accounting-related laws and regulations, and establish and promote information security standard system and service provider qualification review system. On the other hand, the government needs to assess the risk of cloud computing platform with high standards before they operate it. They should adopt the appropriate protection system according to enterprise information security level, so that the platform can transmit and process data effectively under the guidance of relevant laws and regulations, and international advanced technology. China's cloud technology and the implementation of related laws and regulations are still in the initial stage, so the government and relevant functional departments should draw on the international standards and experience in cloud technology combining with the domestic cloud computing problems and define the application development direction of cloud accounting. Moreover, they should gradually improve laws and regulations in the technical level to ensure the security legal environment of cloud accounting data processing, so as to further promote the deep integration of industrialization and informatization.

\section{Conclusion}

As the deepening and extension of cloud technology in the accounting field, cloud accounting has been gradually accepted and recognized by many large, small and medium enterprises. In the new business model, the dominant position of cloud accounting in the financial management in enterprises is obvious to all. At the same time, its emergence also brings many potential risks to enterprises. These risks stem from the basic characteristics of cloud technology and the Internet, but the development of the cloud accounting does conform to the requirements of new business model to the development of financial management. With deep exploration of the cloud technology and improvements of the relevant 
laws and regulations, the maturity of cloud accounting market will gradually increase. It will adapt to the financial management needs of modern enterprises and help enterprises go further. Furthermore, it will become the mainstream model in future financial management.

\section{References}

[1] Yao Tianyang. An Application Research of Cloud Accounting in the Internet Era. Rural Economy and Science-Technology, (18), pp.109-110, 2016.

[2] Li Hui. A Study on the Problems and Countermeasures in the Development of Cloud Accounting. Journal of Xuchang University, (01), pp.121-124, 2016.

[3] Tang Xiaoming. An Application Research of Cloud Accounting in the Big Data Era. Finance and Economy, (02), pp.219-220, 2016.

[4] Yao Zhihui. A Study on the Characteristics and Application Problems of Cloud Accounting in the Big Data Era. Outlook of Science and Technology, (15), pp.1-2, 2015.

[5] Liu Qi. An Application Research of Cloud Accounting Based on the New Business Model. Communication of Finance and Accounting, (22), pp.100-102, 2014.

[6] Cheng Ping, Zhao Zixiao. A Study on the Influence of Cloud Accounting on Small and Medium-size Enterprises and Supplier Selection Strategies. Friends of Accounting, (12), pp.117-120, 2014.

[7] Cheng Ping, He Xuefeng. A Study on the Application of Cloud Accounting in the Accounting Informatization of Small and Medium-sized Enterprises. Journal of Chongqing University of Technology (Social Science Edition), (01), pp.55-60, 2011. 